\title{
Emotions and exercise in adolescent obesity and overweight: systematic review
}

\begin{abstract}
Introduction: Overweight and obesity (OO) generate health problems and public spending that generate conditions such as diabetes and coronary heart disease at an early age and adolescents. Most exercise programs focus on weight reduction, however, does not explain how exercise manages to generate an effect on the emotions of the teenager who can positively impact the body weight loss. The aim of the study was to conduct a literature review to analyze the effect of exercise on the emotions of adolescents with OO. Methodology. The review was stuck to the PRISM

Methodology: EBSCOhost, Redalyc, Scielo, Science Direct, Pub Med, Medline APAsycnet VHL, Springer Link and SCOPUS: databases were reviewed. 2012-2018 year published articles based on exercise alone or combined with food and emotional behavior, making recommendations for the treatment of $\mathrm{OO}$, with participants from 10 to 19 years old were included.

Results: 455 articles were found, 447 were removed for breach of inclusion criteria, leaving 8 items included and analyzed. $12.5 \%$ of the articles were systematic reviews, clinical trials $75 \%$ and $12.5 \%$ of association.

Conclusion: It is not sufficiently clarified how exercise affects the positive and negative emotions in adolescents with OO. The works presented are not free from methodological biases, or establish a specific dose of exercise to reduce negative emotions. Based on exercise alone or combined with food and emotional behavior, making recommendations for the treatment of OO, with participants from 10 to 19 years old.
\end{abstract}

Keywords: emotions, exercise, adolescents, obesity, overweight, systematic review
Volume 2 Issue 3 - 2018

\author{
Erick Landeros-Olvera,' Gudelia Nájera- \\ Gutiérrez, ${ }^{2}$ Rubí Sánchez-Grovas, ${ }^{3}$ Andrea \\ Tzontecomani Rivera ${ }^{4}$ \\ 1,2 Members of the Academic Nursing Education Interventions, \\ Benemérita Universidad Autónoma de Puebla, Mexico \\ ${ }^{3,4}$ Nurses Social Service, National Institute of Neurology and \\ Neurosurgery, Manuel Velasco Suárez, Benemérita Universidad \\ Autónoma de Puebla, Mexico
}

Correspondence: Erick Landeros-Olvera, PhD in Nursing, Benemérita Universidad Autónoma de Puebla, Members of the Academic Nursing Education Interventions, Mexico, Tel +(01222) 2295500 ext 6591, Email erick_landeross@hotmail. com

Received: June 20, 2018 | Published: June 27, 2018

\section{Introduction}

Worldwide, overweight and obesity represent a public health problem given the number of adolescents with these conditions increased by $50 \%$ over previous years. ${ }^{1}$ According to the Pan American Health Organization, ${ }^{2}$ overweight and obesity affect $20 \%$ to $25 \%$ of people under 19 years, respectively.

Health problems and public spending generated by these conditions have led to the creation of exercise programs for weight reduction, most specifically focused to combat the consequences of weight gain as insulin resistance, metabolic syndrome and lipotoxicity, precursors of type 2 diabetes, hypertension and coronary heart disease; diseases the leading cause of death are depicted in increasingly younger ages..$^{3-}$ ${ }^{9}$ However, most exercise programs in adolescents do not consider the emotional or affective changes for body weight control, it is unknown how the exercise can influence the psychological stability of these adolescents. ${ }^{10}$

The literature reports that the emotional and affective aspects may be of importance in the development of overweight and obesity in adolescents, because at this stage of life, behavior is variable, not fixed, so it is not clear how exercise contributes to stabilize negative emotions like depression, low self-esteem, the feeling of rejection or discrimination, anxiety, anger and boredom among others.

Hence the importance of developing exercise programs for weight loss, involving not only biological, but also the emotional or affective. ${ }^{11-13}$ Some studies suggest deepen the understanding of the relationship between Body Mass Index (BMI) and emotions as a means to intervene later in this relationship. ${ }^{14-17}$

In short, although overweight and obesity have been linked to emotional or affective aspects; literature has failed to explain how exercise manages to generate an effect on adolescent emotions that can reach a positive impact on body weight loss. The aim of the study was to conduct a literature review to analyze the effect of exercise in the various weight loss programs on the emotions of overweight and obese adolescents.

\section{Methodology}

It stuck to review the methodology Preferent Reporting Items for Systematic Reviews and Meta-Analyzes. ${ }^{18}$ EBSCOhost, Redalyc, Scielo, Science Direct, Pub Med, BVS Medline, APAsycnet, Springer Link and SCOPUS: The following databases were reviewed. Search terms included the following key words obtained from the MeSH (Medical Subject Headings) and DeCS (Health Sciences Descriptors): "emotions", "exercise", "adolescent", "obesity", "overweight" "randomized clinical trial"; and the combination of these, using a specific search strategy. Searches were Spanish, English and Portuguese, during April 2017 and May 2018.

Published articles of association, systematic reviews, randomized clinical trials, based on exercise or in combination with diet and emotional behavior interventions, which make recommendations for 
the treatment of overweight and obesity, with participants between 10 and 19 years old with obesity were included and / or overweight and were published between 1 January 2012 until 28 May 2018.

The methodological process for systematic reviews developed in PRISMA guidelines are followed. The search was conducted in different databases selected and duplicates were removed manually. Two independent researchers conducted screening items by title and abstract, disagreements regarding the inclusion of items were resolved by consensus; then they analyzed in full text.

Each full-text article underwent an assessment of quality (consistency and plausibility of purpose, results and discussion) and risk of bias (compliance with criteria Consolidated Standards of Reporting Trials ${ }^{19}$ and compliance with criteria PRISMA, this allowed the assessment methodological aspects and the validity of the study.

\section{Results}

455 items were found, 447 of these were removed due to noninclusion criteria, inconsistencies and other reasons (invalid instruments reported); 8 items being included in total and analyzed in this study (Figure 1).
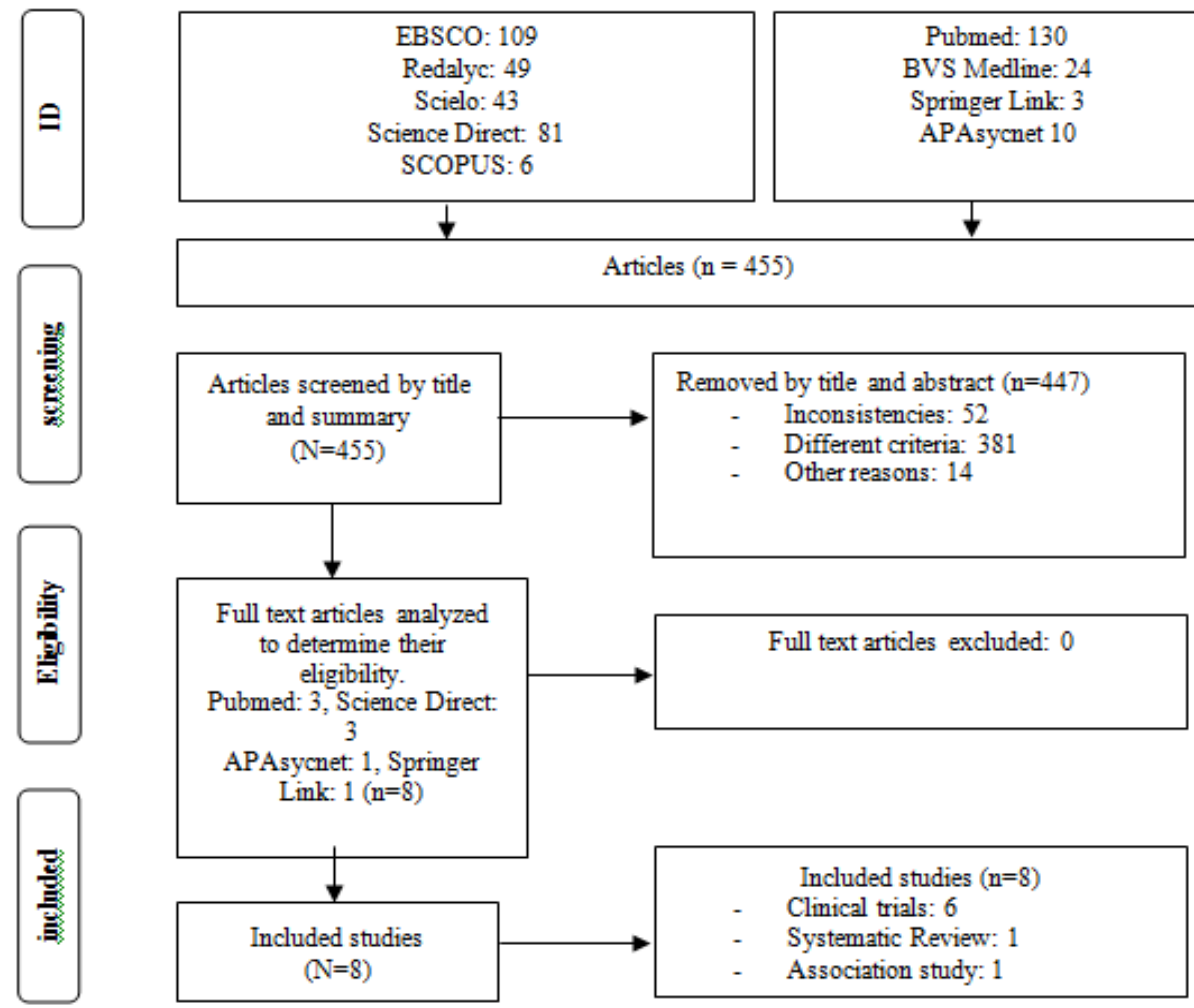

Figure I Flow chart of the process of selection and inclusion of items (PRISM).

\section{General characteristics of the studies}

$12.5 \%$ of the articles were systematic reviews, clinical trials $75 \%$ and $12.5 \%$ of association. In the systematic review 28 articles, of which only 3 are taken into account psychological aspects in children and adolescents are included; in these different physical activity it is carried out over a period of 9 weeks to 2 years of follow-up, with an uptime of 45 to 75 minutes, also mentioned in an article of this review should be performed nutritional and psychological evaluation, all this in order to change the lifestyles of adolescents and promote self-control and self-efficacy.

In the longitudinal association study, exercise was associated with emotional regulation, self-efficacy to be physically active and selfefficacy for physical activity.

Clinical trials included interventions of aerobic exercise, anaerobic and the combination of both types of exercise. In addition, multidisciplinary interventions were made to enhance the effect of exercise interventions, among them are: nutritional counseling, cognitive-behavioral counseling to change unhealthy habits, medical examination and counseling.
The duration of the interventions was variable, from 4 weeks to 2 years; Sessions ranged from once a week to five times a week; the length of sessions ranged from 20 to 60 minutes.

The outcome variables were body weight, BMI, body fat percentage and waist circumference also most interventions showed improvements in emotional well-being, self-esteem, vigor, and decreased emotional role emotions such as anger and anxiety.

Limitations and possible sources of bias items are presented in relation to the study design, no inclusion of the influence of hormones by sex (androgens and estrogens) on weight gain, adherence to the prescription of exercise, lack of group control small samples, lack of tools to identify emotions, financing the study, differences between groups to compare due to the non-equivalence, difficulties in the role of facilitators in the intervention. Then the results of each item selected in the following table are presented to facilitate interpretation of each (Table 1). 
Table I Characteristics of studies.

\begin{tabular}{|c|c|c|c|c|c|}
\hline Author & Design & Participants & Duration & Interventions & Results \\
\hline Rocha et al. ${ }^{13}$ & $\begin{array}{l}\text { Systematic } \\
\text { review. }\end{array}$ & $\begin{array}{l}28 \text { items, of } \\
\text { which } 3 \text { handle } \\
\text { psychological } \\
\text { aspects for } \\
\text { children and } \\
\text { adolescents. } \\
\text { a) Dreimane D, et } \\
\text { al. } 2008 \\
\text { b) O'Connor J, et } \\
\text { al. } 2008 \text {. } \\
\text { c) Vignolo M, et al. } \\
2007 .\end{array}$ & $\begin{array}{l}\text { a) Twelve } \\
\text { weeks. } \\
\text { b) Two years. } \\
\text { c) Nine } \\
\text { weeks. }\end{array}$ & $\begin{array}{l}\text { a) exercise program with eight sessions of } \\
90 \text { min / wk. orientation behavior change, } \\
\text { healthy habits and physical activity (PA) } \\
\text { diversified } 45 \text { min, } 3 \text { times / wk. Child } \\
\text { Health Questionnaire which was subdivided } \\
\text { into scales, one evaluating emotional well- } \\
\text { being was applied. } \\
\text { b) exercise program dietary } \\
\text { recommendations } 7 \text { sessions of } 75 \text { minutes } \\
\text { per week in the first month, then } 60 \text { min } \\
\text { daily AF and guidance for self-esteem model } \\
\text { Cognitive Behavioral Therapy (CBT) } \\
\text { c) nutritional and psychological evaluation, } \\
\text { through which the adolescent modifying } \\
\text { your lifestyle for weight reduction and the } \\
\text { promotion of self-control and self-efficacy. }\end{array}$ & $\begin{array}{l}\text { a) Improvements in emotional } \\
\text { well-being and behavior were } \\
\text { positively correlated with } \\
\text { weight loss } \\
\text { ( } P=0.005) \text {. } \\
\text { b) Statistically significant } \\
\text { improvement in self-esteem, } \\
\text { psychological aspects and } \\
\text { practices AF ( } P<.05 \text { ). } \\
\text { c) Positive changes in the } \\
\text { emotional and social aspects } \\
\text { related to the behavior } \\
\text { of obesity. Where to start } \\
\text { problems of anxiety and } \\
\text { depression in children and } \\
\text { adolescents were found, } \\
\text { obtaining at the end statistically } \\
\text { significant changes ( } P<.02 \text { ). }\end{array}$ \\
\hline
\end{tabular}

Four groups were used, of which three were exercise intervention (attending the gym 4 times / week). To assess changes in depression, self-esteem, and certain emotions like anger or vigor.

GI.Aerobic group through treadmill, elliptical machines ergometers training began moving gradually from 20 to 45 adolescents between 14 and controlled and 18 years ( 213 randomized females), with clinical trial. more than 95 Body Mass Index (BMI) according to age and sex percentile. weeks heart rate, heart rate monitoring. $\mathrm{G} 2$. Anaerobic group or resistance training was 20 to $45 \mathrm{~min}$. per session 7 exercises using weights machines or free weights, progressing two sets of 15 repetitions to twenty-two minutes and $65-85 \%$ of resistance maximum moderate intensity, increasing to 3 sets of 8 repetitive high resistance.

G3. Group 3 combined aerobic and anaerobic exercise sessions with eight mixing the above two routines ( $\mathrm{GI}$ and $\mathrm{G} 2$ ).

28 Judo sessions weekly one-hour training was conducted by a different personal trainer in each of the 3 groups. The sessions were divided into 2 phases: First phase of playful elements, strength training and flexibility skills. Second phase consisted specifically judo throwing and catching. They used force and difficulties questionnaire (SDQ or CFD) is divided into subscales within which emotional problems (mainly concerns and anxiety) and temperament problems are.
In all groups the feeling of anger significantly decreased, G2 showed a significant reduction in depressive symptoms in six months $(p=.02)$.

In GI, G2 groups G3 force increased significantly compared to G4 $(p<0.05)$, this is explained by a time of 6 months $(p<.001)$. Changes in mood of initial data at 6 months were: anger, force and self-esteem being statistically significant in the GI,G2,G3 ( $p=0.00$ I); however changes in depression only observed in G2 ( $p=.02$ )

Comparison of psychological variables (emotional problems) before and after the intervention showed a shift toward a better quality of life related to health $(p=.055)$. Parents also reported fewer behavioral problems $(p<.001)$, pair problems $(p<.00 I)$ and a smaller sum score for total difficulties SDQ $(p<.001)$ after participating in the operation. Changes in total SDQ difficulties exhibited a significant mean difference between the baseline and 6 months $(p=0.00 \mathrm{I})$ and between baseline and 12 months $(p<.001)$. 


\section{Twelve obese adolescents hospitalized $(5$ \\ $\begin{array}{lll}\text { Reece et al. }{ }^{26} & \begin{array}{l}\text { nonrandomized } \\ \text { pilot study. }\end{array} & \begin{array}{l}\text { males and } 7 \\ \text { females) with an }\end{array}\end{array}$ pilot study. average age of 15 years with an average BMI of $43.5 \pm 3.5 \mathrm{~kg} / \mathrm{m} 2$ the insertion of the balloon 6 months during placement of the balloon and two months after the maintenance phase. In addition Balke protocol was applied to assess cardiorespiratory capacity and each test ended when the teenager could not continue the activity. \\ with a program interven-ing six months. Participants constantly walk at a speed of 3 miles per hour starting with a gradient of $6 \%$, which was increased by $2 \%$ every 2 minutes. \\ Inventory quality of life related to health through a state evaluates I5 items multidimensional including physical, emotional, social and academic welfare. Self-perception was assessed through the questionnaire Physical self-perception profile in children and youth).}

The sample

Randomized

Melnyk et al. ${ }^{25} \& \mathrm{Am} \mathrm{J}$ Prev Med controlled trial Prospective, blind. consisted of 779 adolescents aged 14- 16 years with average BMl of $24.43 \pm 5.92 \mathrm{~kg}$ / $\mathrm{m} 2$

COPE program includes 15 educational sessions, a development program of kick-boxing movements). They also used pedometers asking teens to increase their group (G-COPE) was given the COPE

\section{fifteen}

weeks an intervention that included physical activity of families and eating behavior is performed,

The participant and their families received an intervention mainly focused on the participant, which consisted in an intensive program of lifestyle support for 9 months; starting one month before cognitive behavioral skills guided by theory and physical activity. Each session was I5-20 minutes of physical activity (walking, dancing, pace by $10 \%$ every week. The experimental program and control group "Healthy Teens" (HT) was given the manual without physical activity or educational intervention.

Eight male

Brazilian

adolescents with

Lofrano- Randomized a mean age \pm

Prado et al. controlled trial 2.06 de 15.44

obese subjects

with an average

$\mathrm{BMI}$ of $33.06 \pm$

$4.78 \mathrm{~kg} / \mathrm{m} 2$
Four weeks.
Each subject underwent three experimental trials every 7 days: I) Control, sitting for 2 hours; 2) low intensity exercise treadmill (LEL) - exercise $10 \%$ below the ventilatory threshold (VT); 3) High-intensity exercise in treadmill $(\mathrm{PIH})$ - $10 \%$ exercise above VT. The LIE and PIH, sessions energy expenditure (EE) was set to $350 \mathrm{kcal}$. Each participant served as his own control. The experiment was started after 3 sessions on the treadmill.
Emotional well-being was given a significant difference from baseline at 6 months $(p<.05)$ and 12 months to 24 months there was no statistical significance ( $p>05)$.

improvements are shown in physical esteem (mean difference $0.33 d=0.8, p=0.358$ ).
The results in the COPE post intervention group showed no differences Self-reported by Beck Inventory for anxiety (FI, $682,0.10$,

$p=0.75)$ and depression (FI

$0.687,1.58$,

$p=0.21$ ). Furthermore adolescents with scores very high pre-intervention depression scores were significantly lower depression post-intervention compared to Healthy Teens (FI.I $=6.98$, $\mathrm{p}=.02$ ) group.

There was no significant difference between groups at 6 months after surgery self-reported depression and anxiety.

Control group reduced trait anxiety (I.0 (-4.0-I7.0) and improved vigor (I8.0 (10.0-23.0, $p \leq 0.05$.)

By contrast, the group that performed exercise high and low intensity increased anxiety (5.5 (-4.0-29.0) (9.0 (0.0-30.0), P $=.01$ and decreased vigor (I 3.5 (8.0-22.0) $p \leq 0.05$.) (I2.0 (I.019.0), $\mathrm{p} \leq 0.05$.)

No differences were observed between trials, with the exception of fatigue

That is to say, exercise can increase anxiety (trait / state), decrease the effect when highintensity exercise is performed. 


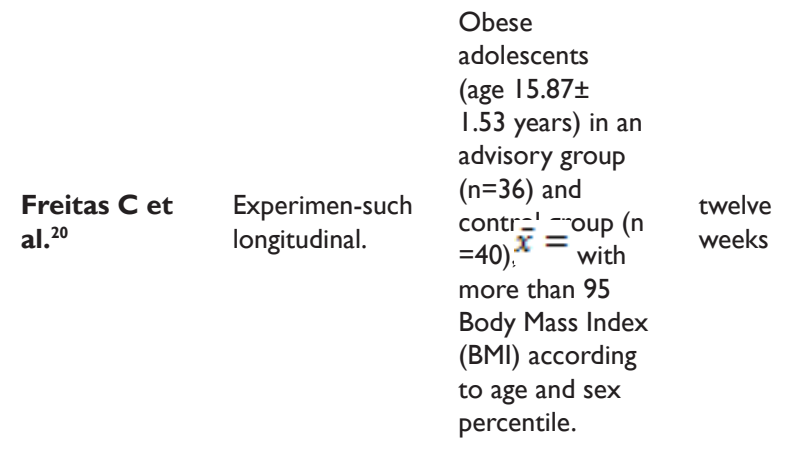

The study

included 602

participants

Isasi RC et al. transversal Schools in the associative Bronx, NY.

Participants were

betven 11 ant
The sample was divided into two groups:

The experimental group or counseling had a multidisciplinary intervention:

I. Clinical Consulting attending I time per month with the endocrinologist.

2. Nutrition education with trained dietitian for I hour each week

3. Aerobic training supervised: on a treadmill and supervised by physical educators three times a week (36 sessions in total) 4. Counseling for one hour each week The control group had no counseling multidisciplinary intervention.
As for the emotional role assessed on the quality of life questionnaire, the baseline $\bar{x}$ ore in group counseling ( $\bar{x}=77.77+32.85)$ and aft 12 weeks of intervention ${ }^{x}=$ $87.96 \pm$ 19.76) compared to the $-\rightarrow$ ntrol group baseline score ( $\bar{x}=68.33 \pm 38.45)$ and after 12 weeks of intervention $(62.56$ $\pm 17.7 \mid=)$ was statistically significant $(p=0.05)$. By taking into account the whole quality $-\bar{x}$ life questionnaire found that $\bar{x}_{\text {multidisciplinary treatment }}$ is more effective in improving quality of life compared with a treatment that does not include psychological counseling.

Emotional regulation is positive towards the efficacy to be physically active, and the efficacy is significant for physical activity ( $\beta$ for indirect effect $=10, p=$ $.001)$. However it is reverse in emotional regulation depressive symptoms and depressive symptoms from time to more sedentary $(\beta=-.04$ for effect, $\mathrm{p}=.002$ )

To be physically active was lower among girls $(\beta=-.16, p=$ $.00 \mathrm{I}$ ). higher levels of depressive symptoms in girls $(\beta=.10, p=$ $.05)$ were observed.

No association of emotional regulation and body mass index (BMI) was found.

\section{Discussion}

The objective was to analyze the effect of exercise practiced in the various programs on the emotions of overweight and obese adolescents. It will be addressed by sections the content of each study used for this article, in the first section systematic reviews, experimental studies, randomized clinical trials with parallel group representative and calculated sample considered strengths to their results were prioritized more attached methodological processes and jobs that did not meet these situations are considered weaknesses, taking into account the criteria of the CONSORT and PRISMA. In the second section the type of intervention (aerobic exercise, gradual and progressive) will be observed. In the third section.

\section{Consort criteria and prisma}

When performing the analysis of items we found that both Golfield, Melink, Recee, Lofrano-Prado, Freitas et al. ${ }^{20}$ used an experimental design, Rocha conducted a systematic review in which only 3 articles address emotional, emotional aspects of self-esteem, only Isasi et al., ${ }^{21}$ used cross-associative design however suggests to conduct experimental studies to test the emotional regulation and exercise.
In reviewing the statement PRISMA found that Rocha provides a structured summary describes the rationale for the review in the context of what is already known about the issue, explicitly talks about the participants, interventions and study design does not indicate whether there is a protocol that can be accessed or registration number, specifies the characteristic of the studies describes all sources of information search as well as the last date of search performed, specifies how the selection was made studies, does not describe methods for extracting data not mentioned risk of bias in individual studies, additional analysis as to the results mentioned characteristics of individual studies, within the discussion of the evidence summary of the main findings, conclusions and limitations of the work is observed but does not show the sources of funding.

By matching the checklist of the information included in the study with experimental methodology, ${ }_{19}$ Lofrano-Prado, Melynk, Reece, Goldfield et al..$^{22-24,12}$ have a degree in which the experimental methodology identifies and present a good summary structured methods, results and conclusions. Regarding the content of the Golfield et al. ${ }^{12}$ \& Geertz et al., ${ }^{25}$ and scientific background Freitas mentioned introduction, explanation, reasoning and specification of 
objectives and hypotheses. For the methodology, Goldfield, Melink and Freitas described design study with parallel groups, including assigning to each group. Golfield, Geertz, Reece, Melynk, Prado and Freitas Lofrano-mentioned criteria for selecting participants. Golfield, Melink and Freitas They pointed out in detail the interventions for each group in order to replicate when and how they were actually administered. Golfield and Melynk dates mentioned the indicator periods of recruitment and follow-up.Únicamente Melynk determined the size of their sample was for power analysis according to literature. None of the studies clarified how it is that: your sample randomized, conducted hidden mechanisms of allocation and masking process. Goldfield and Melynk They pointed out in detail the procedures to allow replication, included when and how they were actually administered. Melynk only determined the size of the sample was by power analysis according to literature. None of the studies clarified how it is that: your sample randomized, conducted hidden mechanisms of allocation and masking process. Goldfield and Melynk They pointed out in detail the procedures to allow replication, included when and how they were actually administered. Melynk only determined the size of the sample was by power analysis according to literature. None of the studies clarified how it is that: your sample randomized, conducted hidden mechanisms of allocation and masking process. Goldfield and Melynk They pointed out in detail the procedures to allow replication, included when and how they were actually administered. ${ }^{26}$

Another point to be analyzed by the checklist were the statistical methods which were used to compare the groups in the primary and secondary results.

Regarding the results Golfield, Geertz and Reece clearly defined evaluations prespecified primary outcomes and the secondary, including how and when evaluated, as well as the change in results after the study has begun. Golfield, Reece, Melynk, LofranoPrado and Freitas shown for each primary and secondary outcome, the results for each group and the effect size and precision (with a confidence interval 95\%). Golfield and Reece indicate adverse effects and unwanted effects in each group.

About the discussion in the studies, all items covered by the limitations of the study, consider the sources of potential bias, generalize the study findings (external validity and applicability, interpret the results by balancing the effects of assumptions and have account other relevant evidence.

Other information provided by the studies are: registration number, access to study and funding. Golfield, Melynk, Lofrano-Prado mention your registration number and name of the study. Golfield, Geertz, Melynk, Lofrano-Prado and Freitas mentioned as protocol can be found to make it accessible. Golfield, Geertz, Melynk and Freitas mention their sources of funding and support.

\section{Interventions}

To analyze interventions studies was evaluated studies counted with: parallel group, control group, masking, measurements and devices or measuring instruments, exercise dose, additional interventions to exercise, sample contamination and risk of bias.

Goldfield, Geertz Melynk and Freitas considered parallel groups. With respect to the control group only they have him Golfield, Lofrano-Prado, Melynk and Freitas. A close masking, Goldfield and Melynk using single-blind mention during his speech however none of the studies reported whether or not succeeded in masking process. Regarding measurements taken during the intervention: Reece, Lofrano-Prado and Melynk size measured by a stadimeter; Reece, Lofrano-Melynk Prado and weighed to adolescencentes with a scale or Filizola; Reece, Lofrano-Prado, Melink the calculated BMI. Percentage body was measured by Golfield and colleagues by magnetic and Lofrano-Prado measured by the bioelectrical impedance resonance; Geertz leg strength measured with a trainer leg Golfield Genius and measured pressing force and leg press; Golfield, LofranoPrado and Freitas measured ventilatory threshold and maximum oxygen to calculate the dose of exercise; Melynk took into account the number of steps per week to keep track of physical activity using a pedometer; Lofrano- Prado uses the Borg scale physical effort to monitor exercise intensity teenager. Intervention according to the researchers should last 20 to 60 minutes, averaging 40 minutes time, it is noteworthy that only Geertz, Reece and Melynk perform physical activities such as judo, hiking, dancing and kick boxing, all other studies use treadmills, ergometers, elliptical machines and free weights. Some additional physical activity interventions were: nutritional counseling as mentioned Golfield, Lofrano Prado, in addition to controlling Freitas kcal consumption ranging from 250 to $350 \mathrm{kcal}$ it is provided by registered dietitians; Freitas also included interventions counseling and medical monitoring by an endocrinologist.

As for sample contamination none of the studies mentioned sample or if your sample was contaminated or had some risk. Some of the risks of bias in the studies were: small sample, no randomization of the sample, not taking into account hormones, fidelity intervention by facilitators and poorly implemented using questionnaires for the variable.

\section{Emotions}

Another aspect to assess studies without doubt the most important of this review, arises from the following questions: Does exercise influence emotions?, Really studies specifically focus on emotions? On the one hand, according to the literature review studies do not refer to or mention that emotions improve the dose of exercise, as mentioned Goldfield and his collaborators changing psychological health is more closely associated with fat reduction body that changes in fitness or strength. It is unclear how that emotions are modified through an exercise intervention.

On the other hand the analyzed studies do not define emotions as a variable outcome, in other words many of these studies encompass emotions generally in concepts such as self-esteem, psychological well-being, symptoms of depression, psychological health, symptoms of anxiety, quality of life and emotional well-being.

\section{Conclusion}

According to the results that threw the literature review to analyze the effect of exercise on the emotions of adolescents with overweight and obesity, is not sufficiently clarified how exercise affects the positive and negative emotions, without englobarlas or sort together, plus programs have not been raised under an experimental methodology with parallel and controlled, with masked interventions and random selection of study subjects who meets the criteria checklist of the information included in a study methodology experimental (CONSORT 2010). The works presented are not free of methodological bias and a dose of specific exercise is not set to decrease negative emotions. 


\section{Acknowledgements}

None.

\section{Conflict of interest}

The Author declares no conflict of interests.

\section{References}

1. https://stopalaobesidad.com/tag/2014/

2. Pan American Health Organization, 2014 Action Plan for the prevention of obesity in childhood and adolescence. 2018.

3. Lecube A, Monereo S, Rubio MP, et al. Diagnostic prevention an treatment of obesity. Positioning of the Spanish Society for the Study of Obesity. Endocrinology, Diabetes and Nutrition. 2016;64(1):15-22.

4. Camacho CA, Arm SJ, Camacho CM, et al. Effects of high intensity interval training on fat mass parameters in adolescents. Spanish Journal of Public Health. 2016;21(90):1-9.

5. Franco LF, Rubio PN, Oyón CM. Adolescents with normal weight and obesity: analysis of differences in physical activity, cardiovascular endurance, family characteristics, personal self. 2014;31(6):378-383.

6. Landeros OE, Lopez AJ, Nava G, et al. Effect of cardiovascular exercise in women with obesity on concentrations of adiponectin. leptin and tumural factor-alpha necrosis. 2013;84(3):177-182.

7. Pbert LS. Druker, B. Barton KL, et al. A school-based program for overweight and obese adolescents: a randomized controlled trial. J Sch Health. 2016;86(10):699-708.

8. Aguilar MJ, Ortegón A, Mur N, et al. Physical activity programs to reduce overweight and obesity in children and adolescents; systematic review. BMJ open. 2014;30(4):727-740.

9. Gow M, Baur L, Ho M, et al. Can early weight loss, eating behavior and socioeconomic factors predict successful weight loss at 12- and 24-months in adolescents With obesity and insulin resistance in a participating randomized controlled trial. Int J Behav Nutr Phys Act. 2016;13:43.

10. Brennan L, Murphy KD, Shaw KA, et al. Psychological interventions for overweight or obesity (Cochrane Library). 2014.

11. Annesi JJ, Mareno N. Indirect effects of exercise on eating emotional through psychological predictors of weight loss in women. Appetite. 2015;95:219-27.

12. Goldfield GS, Kenny GP, features AS, et al. Effects of aerobic training, resistance training, or both on psychological health in adolescents with obesity: the hearty randomized controlled trial. J Consult Clin Psychol. 2015;83(6):1123-1135.

13. Rocha D, Martin MM, Carbonell BA. Effects of intervention programs focused on the treatment of overweight/obese children and adolescents. Sports Medicine. 2013;7(1):33-43.
14. Katz, Anger MV. Relationship between BMI, perceived emotions, styles intake and taste preferences in an adult population. 2015;16:31-36.

15. Muñoz S, Vega C, Berra E. Characterization of stress, emotions and coping in adolescents with different types of IMC. 2015;12(2):268-280.

16. Lazarevich I, Camacho IM, Velazquez AM, et al. Psychometric Characteristics of the Eating an Appraisal Due to Emotions and Stress Questionnaire and obesity in Mexican university students. Nutr Hosp. 2015;31(6):2437-2444.

17. Padros F, Navarro G, Garcidueñas D. Psychometric properties of the scale of guilt for obesity or overweight for Children and Adolescents (ECOSNA). 2016.

18. Urrutia G, Bonfill X. PRISMA statement: A proposal to improve the publication of systematic reviews and meta-analyzes. Journal Clinical Medicine. 2010;135(11):507-511.

19. Carbo C, Augustovski AF. CONSORT 2010 Statement: Update list for reporting randomized parallel group clinical trials. Journal Clinical Medicine. 2010;137(5):213-215.

20. Freitas C, Gunnarsdottir T, Fidelix Y, et al. Effects of a pshychological intervetnion on the quality of life obese adolescents under a multidisciplinary treatment. J Pediatr (Rio J). 2016;93(2):185-191.

21. Isasi CR, Ostrovsky NW, Wills TA. Eating Behaviors The association of emotion regulation With lifestyle behaviors in inner-city adolescents. Eating Behaviors. 2013;14(4):518-521.

22. Lofrano PMC, Hill JO, Joseph H, et al. Acute effects of aerobic exercise on mood and hunger feelings in male obese adolescents: a crossover study. Int J Behav Nutr Phys Act. 2012;2-7.

23. Melnyk BM, Jacobson D, Kelly S, et al. Promoting healthy lifestyles in high school adolescents. American Journal of Preventive Medicine. 2013;45(4):407-415.

24. Reece LJ, Sachdev P, Copeland RJ, et al. Intragastric ballon as an adjuct to lifestyle support in severely obese adolescent; impact on weight, physica activity, cardiorespiratory fitness and psychosocial well-being. Int J Obes (Lond). 2017;41(4):591-597.

25. Geertz W, Dechow A, Pohl E, et al. Physical and psychological well-being in overweight children participating in a long-term intervention based on judo practice physical and psychological well-being in overweight children participating in a long-term intervention based on judo practice. 2017;7(1):85-100.

26. Lee, Lee JY. The association of body image distortion with behaviors weight control diet behavior, physical activity, sadness, suicidal ideation and high school students among korean: a cross-sectional study. $B M C$ Public Health. 2016;16:39. 